\title{
Ameloblastoma of the Jaws: A Retrospective Analysis of 340 Cases in a Malaysian Population
}

\author{
Chong Huat Siar, BDS, MSc, FDSRCPS, FRCPath, * \\ Shin Hin Lau, BDS, MSc, FDSRCS, † and \\ Kok Han Ng, BDS, MSc, FDSRCPS, FRCPath $\neq$
}

Purpose: Ameloblastoma of the human jaw is an uncommon but clinically significant odontogenic epithelial neoplasm. The aim was to analyze the clinicopathologic characteristics of ameloblastoma in a Malaysian population.

Materials and Methods: This is a retrospective study (1993 through 2008) of consecutive ameloblastoma cases accessioned in 2 main oral pathology diagnostic centers: the Unit of Stomatology, Institute for Medical Research and the Department of Oral Pathology, Oral Medicine, and Periodontology, Faculty of Dentistry, University of Malaya, Kuala Lumpur, Malaysia. Data on patient demographics, tumor location, symptomology, duration, radiographic appearance, preoperative diagnosis, clinicopathologic subtypes, treatment, and recurrence were analyzed.

Results: Three hundred forty cases of ameloblastoma were reviewed. These were from 197 male patients (57.9\%) and 143 female patients (42.1\%), with a male-to-female ratio of 1.4:1. A wide age range (7 to 85 years), mean onset age of $30.3 \pm 16.3$ years, and peak incidence in the second decade of life were recorded. Most were mandibular tumors $(\mathrm{n}=311 / 340,91.5 \%)$. These consisted of $95(28 \%)$ unicystic ameloblastomas, 221 (65\%) solid/multicystic ameloblastomas, 22 (6.4\%) desmoplastic ameloblastoma, and 2 (0.6\%) peripheral ameloblastomas. Unicystic ameloblastoma (41.1\%) and solid/multicystic ameloblastoma (52.0\%) mostly affected Malays patients, whereas desmoplastic ameloblastoma (59.1\%) was prevalent in Chinese patients. Unicystic ameloblastoma (56.8\%) and solid/multicystic ameloblastoma (47.1\%) occurred predominantly in the body and posterior mandible, whereas desmoplastic ameloblastoma (36.4\%) preferentially involved the anterior jaw segment. Most tumors presented as multilocular radiolucencies (36.8\%). Enucleation ( $\mathrm{n}=42 / 92$, 45.7\%) was the treatment of choice. About 18 cases (13.3\%) presented with recurrence.

Conclusions: Because ameloblastoma subsets differ in their biologic behavior, the present data are significant as baseline references for clinicians and pathologists.

(c) 2012 American Association of Oral and Maxillofacial Surgeons

J Oral Maxillofac Surg 70:608-615, 2012

In the recent histologic classification of odontogenic tumors from the World Health Organization (WHO), ameloblastoma is defined as a benign, locally invasive epithelial odontogenic neoplasm of putative enamel organ origin. ${ }^{1,2}$ It is the second most common odontogenic neoplasm and accounts for approximately
$11 \%$ to $18 \%$ of all odontogenic tumors. There are 4 distinct clinicopathologic subtypes: unicystic ameloblastoma (UA), solid/multicystic ameloblastoma (SMA), and peripheral and malignant forms. ${ }^{1}$ SMA and UA form the 2 major subsets. ${ }^{1,2}$ SMA has great infiltrative potential and a higher recurrence rate. In contrast, UA
*Professor and Head, Department of Oral Pathology, Oral Medicine, and Periodontology, Faculty of Dentistry, University of Malaya, Kuala Lumpur, Malaysia.

†Consultant, Oral Pathologist and Head, Unit of Stomatology, Institute for Medical Research, Jalan Pahang, Kuala Lumpur, Malaysia.

$\ddagger$ Former Consultant, Oral Pathologist and Director, Institute for Medical Research, Jalan Pahang, Kuala Lumpur, Malaysia.
Address correspondence and reprint requests to Dr Siar: Department of Oral Pathology, Oral Medicine, and Periodontology, Faculty of Dentistry, University of Malaya, 50603 Kuala Lumpur, Malaysia; e-mail: chsiar@gmail.com (C) 2012 American Association of Oral and Maxillofacial Surgeons 0278-2391/12/7003-0\$36.00/0 doi: 10.1016/i.joms.2011.02.039 
has an odontogenic cystlike behavior, occurs at a younger age, and has a lower recurrence rate.

Malaysia, located at the southernmost tip of the Asian continent, is a multiracial, multicultural nation with a population of about 28 million. The 3 main racial groups are the Malays (65.0\%), Chinese (26.0\%), and Indians (8.0\%). In the Malaysian capital city of Kuala Lumpur, there are 2 main oral pathology biopsy diagnostic centers. The Unit of Stomatology at the Institute for Medical Research was established in 1967 and subserves as the main oral pathology diagnostic service center for most government-based dental clinics and hospitals in Malaysia. The other diagnostic center is the Department of Oral Pathology, Oral Medicine, and Periodontology at the Faculty of Dentistry, University of Malaya. This department was formed when the first dental school in Malaysia was established in 1972. It offers an oral pathology diagnostic service not only for patients accessioned in the dental school but also for referral cases in the Klang Valley district. The latter refers to Kuala Lumpur and its suburbs and the adjoining cities and towns in the state of Selangor.

Ameloblastoma is a clinically significant tumor in this region and has been the subject of considerable studies. ${ }^{3-7}$ A previous study ${ }^{3}$ examined 401 ameloblastoma cases based on the WHO's 1971 Histological Typing of Odontogenic Tumours, Jaw Cysts and Allied Lesions. ${ }^{8}$ However, little is known about ameloblastoma and its variants based on the new 2005 World Health Organization Classification of Odontogenic Tumours. ${ }^{1}$

The aim of the present study was to retrospectively analyze ameloblastoma cases diagnosed in the 2 aforementioned centers from 1993 through 2008, classify them according to criteria of the 2005 WHO classification, ${ }^{1}$ and determine their clinicopathologic characteristics.

\section{Materials and Methods}

The surgical biopsy records of all histologically diagnosed cases of ameloblastoma archived from January 1993 through December 2008 inclusive were retrieved from the files of the Unit of Stomatology, Institute for Medical Research and the Department of Oral Pathology, Oral Medicine, and Periodontology, Faculty of Dentistry, University of Malaya, Kuala Lumpur, Malaysia. This was a retrospective study that was exempted from institutional review board approval (research grant RG83/09HTM). A patients' age, gender, race, location, clinical signs and symptoms, duration, radiographic appearance, preoperative diagnosis, treatment, and recurrence were abstracted from the case summaries accompanying the biopsy specimens. For analysis of mandibular ameloblastomas, site of occurrence was categorized into anterior (incisalcanine), body (premolar-molar region), posterior (distal to third molar), and bilateral (across midline) regions. For the mandible, the posterior area also included the ramus, angle, coronoid process, and condyle. For maxillary tumors, site was subdivided into anterior (incisal-canine) and posterior (distal to canine) regions. Any tumor involving 2 or more sites was assigned to the region approximating the center of the lesion. Any recurrent tumors arising from these cases were not considered as separate or additional cases. Sections of all primary and recurrent tumors stained with hematoxylin and eosin were retrieved and reviewed to reclassify them according to criteria of the recent WHO classification of odontogenic tumors. ${ }^{1}$

Descriptive statistics were performed to calculate the frequency and percentages of these variables. Age was stratified into various groups at 10-year intervals. Statistical analysis was carried out using SPSS 12.0 (SPSS, Inc, Chicago, IL). The Fisher exact test for differences between 2 groups and the Kruskal-Wallis test for differences among 3 or more groups were used as appropriate. The level of statistical significance was set at $P<.05$.

\section{Results}

\section{CLINICAL FINDINGS}

From the 1,234 cases of odontogenic tumors (excluding keratocystic odontogenic tumors) accessioned over the 16-year study period, 340 histologically confirmed ameloblastomas were analyzed, yielding an incidence of $27.6 \%$. The distribution of these cases according to ethnicity, anatomic location, mean duration, radiologic appearance, and clinicopathologic subtypes are presented in Table 1. Statistical analysis showed significant differences in the distribution of ameloblastoma in relation to ethnicity and anatomic location $(P<.05)$.

Clinical information was available in 135 cases (100\%). Mean duration of clinical symptoms was 13.6 months (range, 4 days to 15 years). A slowly enlarging, painless swelling ( $\mathrm{n}=99,73.3 \%)$ was the most common presenting complaint. Numbness $(\mathrm{n}=7$, $5.2 \%)$, soft tissue growth $(\mathrm{n}=6,4.4 \%)$, discharging sinus $(\mathrm{n}=4,3.0 \%)$, and a nonhealing extraction socket $(\mathrm{n}=1,0.7 \%)$ were uncommon. Only 1 case was asymptomatic.

\section{RADIOLOGIC FINDINGS}

A multilocular radiolucency was the most frequently encountered radiographic appearance (Table 1). Sixteen cases (6.7\%) presented with root resorption and 8 (3.4\%) were associated with unerupted teeth. 
Table 1. SUMMARY OF DATA ON 340 CASES OF AMELOBLASTOMA

\begin{tabular}{|c|c|c|c|}
\hline & Male & Female & Male:Female \\
\hline Total number of cases $(n=340)$ & $197(57.9 \%)$ & $143(42.1 \%)$ & $1.4: 1$ \\
\hline Age (yr), mean (range) & $31.9(8-84)$ & $28.3(7-85)$ & - \\
\hline \multicolumn{4}{|l|}{ Ethnicity $(\mathrm{n}=340,100 \%)$} \\
\hline Malay $(\mathrm{n}=162,47.6 \%)$ & $101(29.7 \%)$ & $61(17.9 \%)$ & $1.7: 1$ \\
\hline Chinese $(n=118,34.8 \%)$ & $59(17.4 \%)$ & $59(17.4 \%)$ & $1: 1$ \\
\hline Indians $(n=24,7.0 \%)$ & $18(5.3 \%)$ & $6(1.7 \%)$ & $3: 1$ \\
\hline Others $(\mathrm{n}=36,10.6 \%)$ & $20(5.9 \%)$ & $16(4.7 \%)$ & 1.2:1 \\
\hline \multicolumn{4}{|l|}{ Anatomic location $(\mathrm{n}=340,100 \%)$} \\
\hline Mandible $(\mathrm{n}=311,91.5 \%)$ & $179(52.6 \%)$ & $132(38.8 \%)$ & $1.4: 1$ \\
\hline Maxilla $(\mathrm{n}=29,8.5 \%)$ & $18(5.3 \%)$ & $11(3.2 \%)$ & $1.6: 1$ \\
\hline Known duration, mean (range) & $13.7 \mathrm{mo}(1 \mathrm{wk}-15 \mathrm{yr})$ & $13.5 \mathrm{mo}$ ( 4 days $-10 \mathrm{yr})$ & \\
\hline \multicolumn{4}{|l|}{ Radiologic appearance $(n=239,100 \%)$} \\
\hline MLRL $(\mathrm{n}=88,36.8 \%)$ & $54(22.6 \%)$ & $34(14.2 \%)$ & 1.6:1 \\
\hline ULRL $(\mathrm{n}=48,20.1 \%)$ & $26(10.9 \%)$ & $22(9.2 \%)$ & $1.2: 1$ \\
\hline RLNOS $(\mathrm{n}=33,13.8 \%)$ & $17(7.1 \%)$ & $16(6.7 \%)$ & $1.1: 1$ \\
\hline Mixed RL-RO (n = 7, 2.9\%) & $5(2.1 \%)$ & $2(0.8 \%)$ & $2.5: 1$ \\
\hline $\mathrm{RO}(\mathrm{n}=1,0.4 \%)$ & $1(0.4 \%)$ & $0(0)$ & - \\
\hline Others $(\mathrm{n}=62,26.0 \%)$ & $38(16.0 \%)$ & $24(10.0 \%)$ & $1.6: 1$ \\
\hline \multicolumn{4}{|l|}{$\begin{array}{l}\text { Ameloblastoma subtypes }(\mathrm{n}=340 \text {, } \\
100 \%)\end{array}$} \\
\hline Solid/multicystic $(\mathrm{n}=221,65.0 \%)$ & $130(38.2 \%)$ & $91(26.8 \%)$ & $1.4: 1$ \\
\hline Unicystic $(\mathrm{n}=95,28.0 \%)$ & $54(15.9 \%)$ & $41(12.1 \%)$ & $1.3: 1$ \\
\hline Desmoplastic $(\mathrm{n}=22,6.4 \%)$ & $13(3.8 \%)$ & $9(2.6 \%)$ & $1.4: 1$ \\
\hline Peripheral $(\mathrm{n}=2,0.6 \%)$ & $1(0.3 \%)$ & $1(0.3 \%)$ & $1: 1$ \\
\hline
\end{tabular}

Abbreviations: ML, multilocular; NOS, not otherwise specified; RL, radiolucency; RO, radiopacity; UL, unilocular.

Siar, Lau, and Ng. Ameloblastoma of the Jaws. J Oral Maxillofac Surg 2012.

\section{PREOPERATIVE DIAGNOSIS}

There were 130 cases (100\%) with known preoperative diagnoses. An ameloblastoma $(\mathrm{n}=103$, $79.2 \%$ ) was the most common diagnosis, followed by dentigerous cyst $(\mathrm{n}=8,6.2 \%)$ and odontogenic keratocyst $(\mathrm{n}=6$ cases, $4.6 \%)$.

\section{PATHOLOGIC FINDINGS}

Four clinicopathologic subtypes of ameloblastoma were identified: UA ( $\mathrm{n}=95,27.9 \%)$, SMA $(\mathrm{n}=221$, 65\%), desmoplastic ameloblastoma (DA; $\mathrm{n}=22$, $6.4 \%)$, and peripheral ameloblastoma $(\mathrm{PA} ; \mathrm{n}=2$, $0.6 \%$ ). Details of their distribution according to age, ethnicity, and anatomic location are shown in Figures 1-3. Mean onset ages of UA, SMA, and DA were significantly different $(P<.05)$. All subtypes showed a male predominance except for UA and SMA, which showed a slight preponderance in Chinese and ethnic minority females, respectively. UA and SMA preferentially affected the body $(\mathrm{n}=90)$ and posterior mandible $(n=68)$, whereas DA exhibited a predilection for the anterior jaw segment $(n=8)$. In SMA, the 2 most common histologic growth patterns encountered were plexiform $(\mathrm{n}=104)$ and follicular $(\mathrm{n}=$ 30). Granular cell $(\mathrm{n}=11)$, acanthomatous $(\mathrm{n}=9)$, and basaloid $(\mathrm{n}=1)$ variants were rare.

\section{TREATMENT AND FOLLOW-UP}

Information on primary treatment was known in 92 cases (100\%). Most were treated conservatively by enucleation and/or curettage ( $\mathrm{n}=42,45.7 \%)$, local excision ( $n=27,29.4 \%)$, or marginal resection $(n=11$, $12.0 \%)$. Segmental resection $(\mathrm{n}=4,4.3 \%)$, hemimaxillectomy ( $\mathrm{n}=4,4.3 \%)$, hemimandibulectomy $(\mathrm{n}=3$, $3.2 \%)$, and decompression ( $\mathrm{n}=1,1.1 \%)$ were the other treatment methods recorded.

Follow-up information was available in 135 cases (100\%). Eighteen cases (13.3\%) presented with recurrence (mean onset age, 7.3 years; range, 1 to 29 years). Patients' data are presented in Table 2. Of these, 3 cases had multiple recurrences. Twenty-three (100\%) recurrent tumors consisting of 6 UAs (26.1\%) and 17 SMAs (73.9\%) were recorded.

\section{Discussion}

In the present study, all 340 cases were classified according to the new 2005 WHO classification. ${ }^{1}$ A search of the English-language literature disclosed few reports that reviewed large series of ameloblastomas per $\mathrm{se}^{9-12}$ or odontogenic tumors ${ }^{13-16}$ in accordance with the new 2005 WHO classification. ${ }^{1}$ Recent ameloblastoma review series have included a multi- 


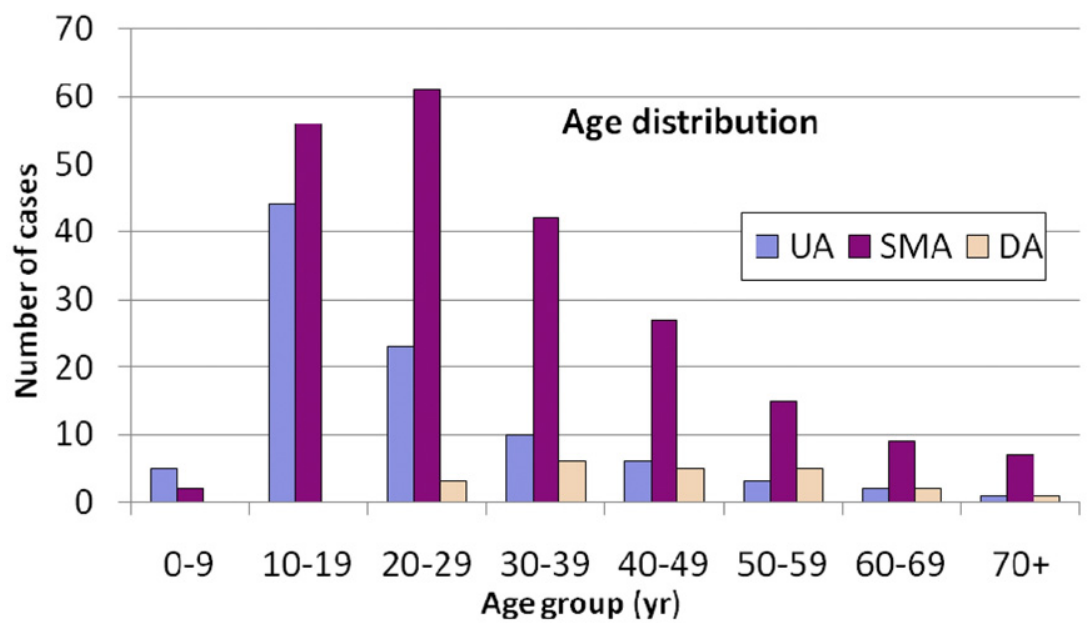

\begin{tabular}{|l|l|l|l|l|}
\cline { 2 - 5 } \multicolumn{1}{c|}{} & UA $(\mathrm{n}=95)$ & SMA $(\mathrm{n}=221)$ & DA $(\mathrm{n}=22)$ & PA $(\mathrm{n}=2)$ \\
\hline Mean age $(\mathrm{yr})$ & $23.7 \pm 13.8$ & $31.7 \pm 16.3$ & $44.8 \pm 13.7$ & $31.5 \pm 23.5$ \\
\hline Age range $(\mathrm{yr})$ & $7-73$ & $11-85$ & $21-72$ & $15-48$ \\
\hline $\begin{array}{l}\text { Peak } \\
\text { incidence }(\%)\end{array}$ & $10-19(46.3)$ & $20-29(27.6)$ & $30-39(27.3)$ & - \\
\hline
\end{tabular}

FIGURE 1. Age distribution of ameloblastoma subtypes. DA, desmoplastic ameloblastoma; PA, peripheral ameloblastoma; SMA, solid/ multicystic ameloblastoma; UA, unicystic ameloblastoma.

Siar, Lau, and Ng. Ameloblastoma of the Jaws. J Oral Maxillofac Surg 2012.

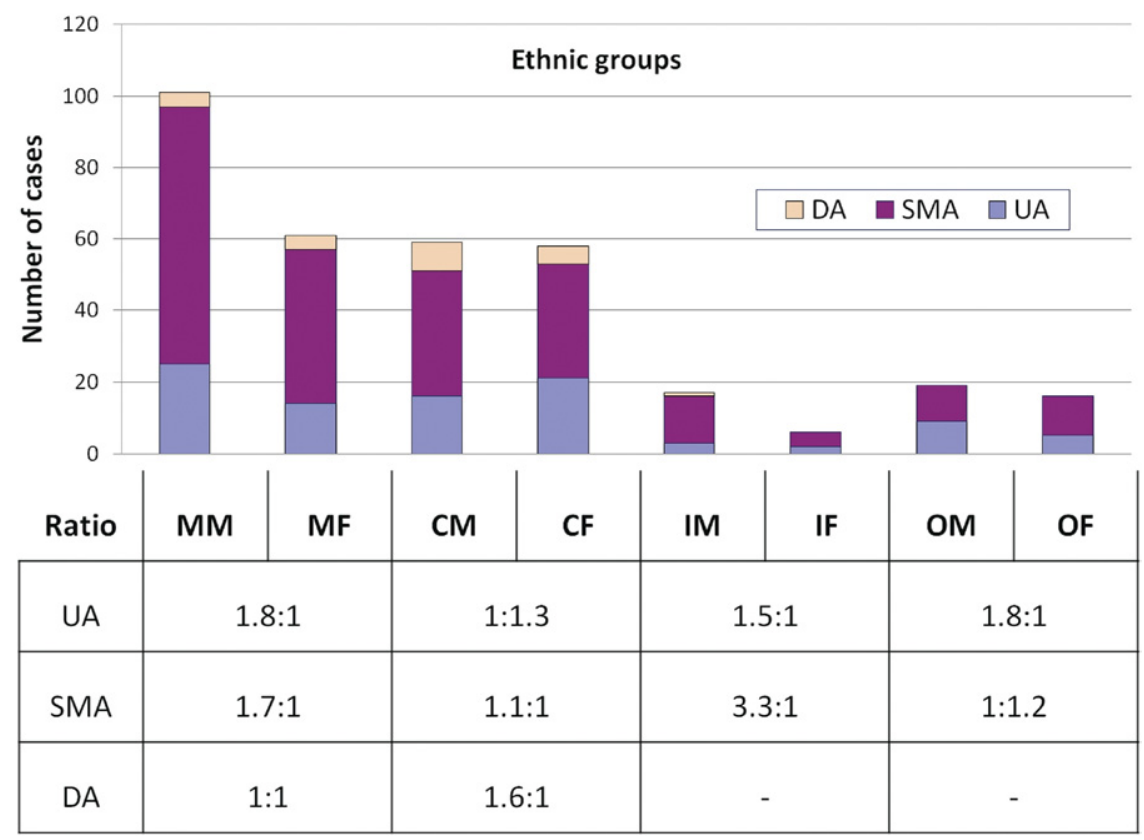

FIGURE 2. Ethnic distribution of ameloblastoma subtypes. CF, Chinese female; CM, Chinese male; DA, desmoplastic ameloblastoma; IF, Indian female; IM, Indian male; MF, Malay female; MM, Malay male; OF, other females; OM, other males; SMA, solid/multicystic ameloblastoma; UA, unicystic ameloblastoma.

Siar, Lau, and Ng. Ameloblastoma of the Jaws. J Oral Maxillofac Surg 2012. 

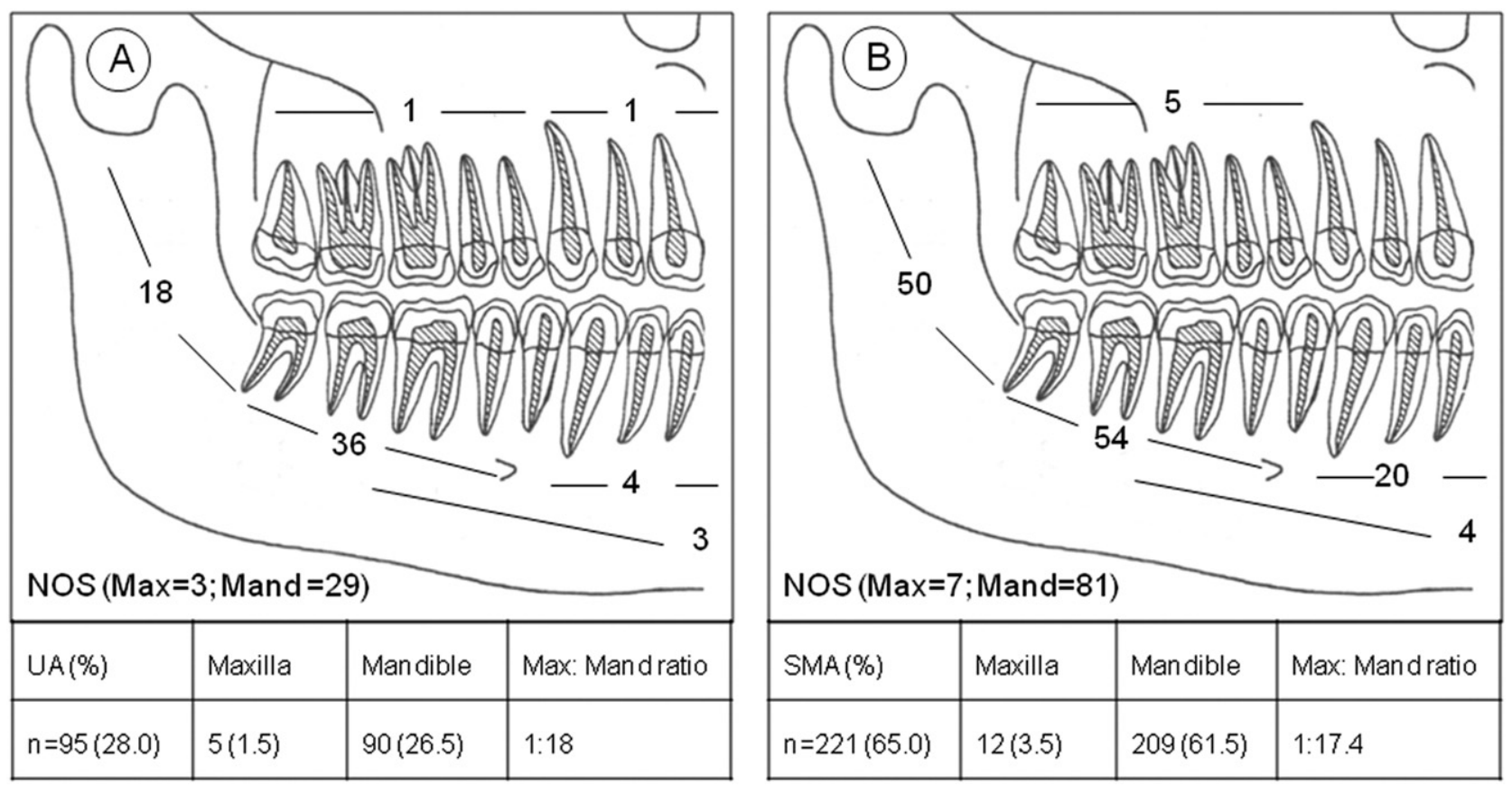

FIGURE 3. Site distribution of $A$, UA and $B$, SMA subtypes. DA, desmoplastic ameloblastoma; Mand, mandible; Max, maxilla; NOS, not otherwise specified; SMA, solid/multicystic ameloblastoma; UA, unicystic ameloblastoma.

Siar, Lau, and Ng. Ameloblastoma of the Jaws. J Oral Maxillofac Surg 2012.

centric Latin-American study on 163 cases of ameloblastoma, ${ }^{9}$ a critical appraisal of 25 cases from a single institution, ${ }^{10}$ a comparative analysis of mandibular (251 cases) versus maxillary (31 cases) ameloblastomas in Sri Lanka, ${ }^{11}$ and a prevalence study of 37 cases in Chinese children and adolescents. ${ }^{12}$ For odontogenic tumor series based on the 2005 WHO classification, these have included a retrospective study of 1,642 cases (inclusive of 661 ameloblastomas) in a Chinese population, ${ }^{13}$ an analysis of 238 odontogenic tumors (inclusive of 57 ameloblastomas) in Brazil ${ }^{14} \mathrm{a}$ review of 1,309 cases of odontogenic tumors (inclusive of 478 ameloblastomas) in a northern Chinese population, ${ }^{15}$ and a prevalence study of 82 odontogenic tumors (inclusive of 34 ameloblastomas) in Egypt. ${ }^{16}$ From these published reports, certain similarities and differences compared with the present data were identified.

It is well-known that the demographic profile of ameloblastoma exhibits considerable geographic variation, and this has been extensively discussed in a meta-analysis ${ }^{2}$ and in other published series. ${ }^{9-23}$ By limiting the present comparison with those studies based on the 2005 WHO classification, the Malaysian ameloblastomas were found to correlate well with other Asian and, to a lesser extent, Egyptian ameloblastomas in showing a high relative frequency, ${ }^{13,15,16}$ a wide age distribution, ${ }^{13,15,16}$ a peak incidence in the second decade of life, ${ }^{11,13,15}$ and slight male predominance. ${ }^{13,15,16}$ In contrast, in Latin American amelo- blastomas, the tumors occurred at a lower frequency, exhibited an almost even gender distribution, and a wide age range. ${ }^{9}$ The present data concurred with previous studies in showing that individuals with UA tended to be younger than those with SMA, ${ }^{1,15}$ whereas patients with DA belonged to an even older age group. ${ }^{8,15}$

It has been suggested that ameloblastomas are more prevalent in blacks and people of Asian descent. ${ }^{2}$ In the present study, although a statistically significant difference in the distribution of ameloblastoma in relation to ethnicity was observed, this racial distribution pattern reflected the local racial population ratio. ${ }^{3}$ In contrast, DA occurred predominantly in Chinese (59.1\%), even though this ethnic group formed $26.0 \%$ of the local racial population. ${ }^{3,8}$ The reason for this racial predilection is unclear.

It is well recognized that ameloblastomas occur more frequently in the mandible than in the maxilla, and that these tumors are located predominantly in the body and posterior mandible., ${ }^{2,9,13-15,17,19}$ In the present study, more than $90 \%$ of ameloblastomas were found in the mandible and most of these tumors were also located in the body and posterior regions. The observed prevalence of DA for the anterior jaw segment agrees with other reported data in the literature. ${ }^{1,4,8,11,15}$ A Chinese study found that the more posterior in the mandible an ameloblastoma was located, the younger the patient was at diagnosis. ${ }^{15}$ In 


\section{Table 2. CLINICOPATHOLOGIC CHARACTERISTICS OF 18 CASES OF RECURRENT AMELOBLASTOMA}

Recurrence Onset* and Treatment

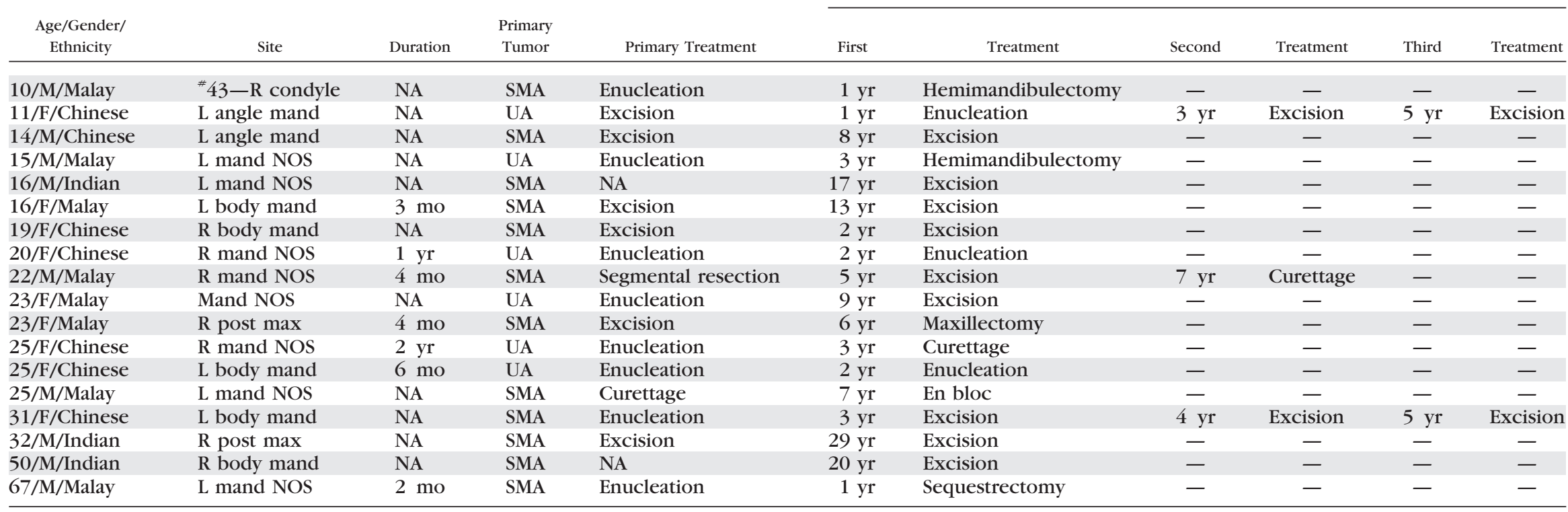

* Onset refers to duration from primary treatment to subsequent recurrence(s).

\#43, mandibular right canine (FDI 2-digit notation system); F, female; L, left; M, male; mand, mandible; max, maxilla; NA, not available; NOS, not otherwise specified; post, posterior; R, right; SMA, solid/multicystic ameloblastoma; UA, unicystic ameloblastoma.

Siar, Lau, and Ng. Ameloblastoma of the Jaws. J Oral Maxillofac Surg 2012. 
the present study, this relation could not be demonstrated.

In tumor duration, the mean for the present series was 13.6 months. This was considerably shorter than the reported mean of 4.5 years in Latin Americans. The difference may be related to the type of diagnostic services available in these centers. Analysis of clinical signs and symptoms in this study disclosed that the most common presenting complaint was a slowly enlarging, painless swelling (73.3\%) and this correlated well with other studies. ${ }^{2,9,13}$ In contrast, in Brazil about $79 \%$ of ameloblastoma were asymptomatic, ${ }^{14}$ whereas most ameloblastomas in $\mathrm{China}^{13}$ and Egypt $^{16}$ reportedly exhibited self-limited growth and did not produce any clinical symptoms.

A multilocular radiolucency was the most commonly encountered radiographic presentation in the present series (36.8\%) and this agreed with other studies. $^{12,13}$ Consequently, an ameloblastoma was also the most frequent preoperative diagnosis made in the present and previous studies. ${ }^{12,13}$

The present distribution pattern of the various ameloblastoma subtypes was broadly comparable with most reported series. ${ }^{9,16}$ As in other studies, PA and other cellular variants of SMA, namely granular cell, basal cell, and acanthomatous forms, were rare. ${ }^{9,12,16}$ Although clear cell differentiation was described in a previous case of $\mathrm{PA},{ }^{4}$ this cellular change was not observed in the present tumor series.

SMA is a locally infiltrating neoplasm and the preferred treatment is wide surgical excision. ${ }^{10}$ In contrast, UA has a cystlike behavior, and a more conservative surgical approach is the treatment of choice. ${ }^{9}$ There are others who recommended that the third histologic subtype of UA (showing intraluminal and intramural proliferations) is an aggressive tumor and therefore should be treated more radically as for SMA. ${ }^{13}$ In the present series, most cases were treated conservatively by enucleation, local excision, or marginal resection.

Ameloblastoma is an enigmatic tumor with a strong tendency to recur after treatment. ${ }^{24-28}$ The recurrence rate $(13.3 \%)$ in the present series was lower than the reported recurrence rate for ameloblastoma, which may range from $15.9 \%$ to $20.6 \%{ }^{2,9}$ It is known that recurrences can take longer than 20 years to become apparent and, therefore, the eventual recurrence rate may be higher. ${ }^{12,29,30}$ Recurrence in ameloblastoma is believed to be the result of several risk factors, notably tumor subtype ${ }^{1,2,26}$ treatment methods, ${ }^{26}$ and tumoral behavior. ${ }^{29}$ Tumors with a follicular, granular, or acanthomatous growth pattern have a reportedly high likelihood of recurrence, whereas desmoplastic, plexiform, and unicystic subtypes have a relatively low recurrence potential. ${ }^{1,2,26}$ As with others, ${ }^{11}$ a similar observation was made in the pres- ent study in that two thirds of recurrent ameloblastoma cases were SMA $(n=12 / 18,66.7 \%)$ and only one third were UA $(n=6 / 18,33.3 \%)$. However, most of these recurrent SMA tumors had a plexiform growth pattern $(\mathrm{n}=8 / 12)$, whereas the remaining exhibited a follicular growth pattern $(n=4 / 12)$, but these numbers were too small for meaningful evaluation of their relative recurrence potential. Furthermore, we were unable to determine the recurrence risk in the other histologic growth patterns because no recurrences were recorded thus far for the acanthomatous form $(\mathrm{n}=9)$, granular form $(\mathrm{n}=11)$, PA $(n=2)$, basaloid form $(n=1)$, and DA $(n=22)$. It is generally known that there is a significant association between treatment and recurrence outcome in ameloblastoma. ${ }^{11,25,30} \mathrm{~A}$ systematic review on recurrence related to treatment modalities of UA found that enucleation alone resulted in the highest recurrence rate $(30.5 \%) .{ }^{25}$ The present study also found that 15 of 18 ameloblastoma cases (83.3\%) that presented with recurrence underwent conservative surgical therapy (enucleation, excision, or curettage) of the primary tumors. Postoperative follow-up for ameloblastoma is of utmost importance because reportedly more than $50 \%$ of recurrences occur within 5 years after treatment. ${ }^{2,12,24}$ This study also demonstrated that 55\% $(n=10 / 18)$ of recurrences occurred within 5 years after primary surgery. It is a well-established fact that the ameloblastoma is a locally invasive neoplasm with a tendency to recur after many years of apparent cure. ${ }^{1,2,12,25}$ Two cases in this series presented with recurrence 20 and 29 years, respectively, after surgical therapy. These observations reaffirmed the insidious biological behavior of this neoplasm and reemphasized the necessity for long-term follow-up. ${ }^{12}$

In summary, 340 cases of ameloblastoma in a Malaysian population were reviewed to determine their clinicopathologic characteristics. Findings showed that their distribution patterns according to age, gender, and site compared favorably with other reported series. The data accrued are useful and of significance as baseline reference to clinicians and pathologists.

\section{Acknowledgments}

The authors thank all clinical specialists at the Ministry of Health, Malaysia, Faculty of Dentistry, University of Malaya and private hospitals/clinics for their case contributions that made this project possible. This study was supported by a grant from the University of Malaya (RG083/09HTM).

\section{References}

1. Gardner DG, Heikinheimo K, Shear M, et al: Ameloblastomas, in Barnes L, Eveson JW, Reichart PA, et al (eds): World Health Organization Classification of Tumours. Pathology and Genetics of Head and Neck Tumours. Lyon, International Agency for Research on Cancer, 2005, p 296

2. Reichart PA, Philipsen HP, Sonner S: Ameloblastoma: Biological profile of 3677 cases. Eur J Cancer B Oral Oncol 31B:86, 1995 
3. Siar $\mathrm{CH}, \mathrm{Ng} \mathrm{KH}$ : Ameloblastoma in Malaysia-A 25-year review Ann Acad Med Singapore 22:856, 1993

4. $\mathrm{Ng} \mathrm{KH}$, Siar $\mathrm{CH}$ : Peripheral ameloblastoma with clear cell differentiation. Oral Surg Oral Med Oral Pathol 70:210, 1990

5. Siar $\mathrm{CH}, \mathrm{Ng} \mathrm{KH}$ : Calcifying and keratinizing ameloblastoma of the maxilla. J Laryngol Otol 105:971, 1991

6. Siar $\mathrm{CH}, \mathrm{Ng} \mathrm{KH}$ : Combined ameloblastoma and odontogenic keratocyst or keratinising ameloblastoma. Br J Oral Maxillofac Surg 31:183, 1993

7. $\mathrm{Ng} \mathrm{KH}$, Siar $\mathrm{CH}$ : Desmoplastic variant of ameloblastoma in Malaysians. Br J Oral Maxillofac Surg 31:299, 1993

8. Pindborg JJ, Kramer IRH, Torloni H: Histological Typing of Odontogenic Tumours, Jaw Cysts and Allied Lesions. International Histological Classification of Tumours. No 5. Geneva, World Health Organization, 1971

9. Ledesma-Montes C, Mosqueda-Taylor A, Carlos-Bregni R, et al: Ameloblastomas: A regional Latin-American multicentric study. Oral Dis 13:303, 2007

10. Hertog D, van der Waal I: Ameloblastoma of the jaws: A critical reappraisal based on a 40-years single institution experience. Oral Oncol 46:61, 2010

11. Gunawardhana KSND, Jayasooriya PK, Rambukeweka IK, et al: A clinico-pathological comparison between mandibular and maxillary ameloblastomas in Sri Lanka. J Oral Pathol Med 39: 236, 2010

12. Zhang J, Gu Z, Jiang L, et al: Ameloblastoma in children and adolescents. Br J Oral Maxillofac Surg 48:549, 2010

13. Jing W, Xuan M, Lin Y, et al: Odontogenic tumours: A retrospective study of 1642 cases in a Chinese population. Int J Oral Maxillofac Surg 36:20, 2007

14. Avelar RL, Antunes AA, Santos T, et al: Odontogenic tumors: Clinical and pathology of 238 cases. Braz J Otorhinolaryngol 74:668, 2008

15. Luo HY, Li TJ: Odontogenic tumors: A study of 1309 cases in a Chinese population. Oral Oncol 45:706, 2009

16. Tawfik MA, Zyada MM: Odontogenic tumors in Dakahlia, Egypt: Analysis of 82 cases. Oral Surg Oral Med Oral Pathol Oral Radiol Endod 109:e67, 2010

17. Fernandes AM, Duarte EC, Pimenta FJ, et al: Odontogenic tumors: A study of 340 cases in a Brazilian population. J Oral Pathol Med 34:583, 2005
18. Olgac V, Koseoglu BG, Aksakalli N: Odontogenic tumours in Istanbul: 527 cases. Br J Oral Maxillofac Surg 44:386, 2006

19. Okada H, Yamamoto H, Tilakaratne WM: Odontogenic tumors in Sri Lanka: Analysis of 226 cases. J Oral Maxillofac Surg $65: 875,2007$

20. Siriam G, Shetty R: Odontogenic tumors: A study of 250 cases in an Indian teaching hospital. Oral Surg Oral Med Oral Pathol Oral Radiol Endod 105:e14, 2008

21. Poon CSP, Wu PC, So MKP: Ameloblastoma in Hong Kong Chinese. Hong Kong Med J 2:172, 1996

22. Lu Y, Xuan M, Takata T, et al: Odontogenic tumors. A demographic study of 759 cases in a Chinese population. Oral Surg Oral Med Oral Pathol Oral Radiol Endod 86:707, 1998

23. Adebiyi KE, Ugboko VI, Omoniyi-Esan GO, et al: Clinicopathological analysis of histological variants of ameloblastoma in a suburban Nigerian population. Head Face Med 2:42, 2006

24. Olaitan AA, Arole G, Adekeye EO: Recurrent ameloblastoma of the jaws. A follow-up study. Int J Oral Maxillofac Surg 27:456, 1998

25. Lau SL, Samman N: Recurrence related to treatment modalities of unicystic ameloblastoma: A systematic review. Int J Oral Maxillofac Surg 35:681, 2006

26. Hong J, Yun PY, Chung IH, et al: Long-term follow up on recurrence of 305 ameloblastoma cases. Int J Oral Maxillofac Surg 36:283, 2007

27. Huang IY, Lai ST, Chen $\mathrm{CH}$, et al: Surgical management of ameloblastoma in children. Oral Surg Oral Med Oral Pathol Oral Radiol Endod 104:478, 2007

28. Sammartino G, Zarrelli C, Urciuolo V, et al: Effectiveness of a new decisional algorithm in managing mandibular ameloblastomas: A 10-years experience. Br J Oral Maxillofac Surg 45:306, 2007

29. Martins WD, Martins D: Recurrence of an ameloblastoma in an autogenous iliac bone graft. Oral Surg Oral Med Oral Pathol Oral Radiol Endod 98:657, 2007

30. Eckardt AM, Kokemüller H, Flemming P, et al: Recurrent ameloblastoma following osseous reconstruction-A review of twenty years. J Craniomaxillofac Surg 37:36, 2009 